\title{
Progressive Retrogression: Science, Technology, Dress Sense and Fashion Taste amongst Polytechnic Students in Ghana
}

\author{
Maud Schall1, Seth Christopher Yaw Appiah2* \\ ${ }^{1}$ Faculty of Creative Art, Kumasi Polytechnic, Kumasi, Ghana \\ ${ }^{2}$ Department of Sociology and Social Work, Faculty of Art and Social Sciences, Kwame Nkrumah University of \\ Science and Technology, Kumasi, Ghana \\ Email: Schallmaud@yahoo.com, “Sychrist2007@gmail.com
}

Received 6 January 2016; accepted 12 April 2016; published 15 April 2016

Copyright (C) 2016 by authors and Scientific Research Publishing Inc.

This work is licensed under the Creative Commons Attribution International License (CC BY). http://creativecommons.org/licenses/by/4.0/

(c) (;) Open Access

\begin{abstract}
Background: The dressing or fashion style of tertiary students has become an important issue of much concern in this contemporary era amidst technological advancement. This study examines polytechnic students perspective on the effect science and technology has on dress sense and fashion taste. Methods: The design was a cross-sectional non-experimental survey of 102 polytechnic students between the ages of 15 - 29 years with ample knowledge on dress sense. The sample consisted of 40 male (39.2\%) and 62 female $(60.8 \%)$ students who were enrolled by using a multistage cluster sampling technique according to departments and academic levels. Results: The study found that there was an association between science and technology influence and dress sense ( $53.7 \%$ approval vs. $46.7 \%$ disapproval), however this was not statistically significance $\left[x^{2}=\right.$ $0.21, p \leq 0.005]$. Again the relationship between the future influence of science and technology on the dress sense of students was examined using Spearman's rank correlation coefficient since the two variables of interest were measured at continuous and categorical levels. The study identified a very weak negative correlation between the future influence of science and technology on dress sense and how better students dress will be than now $[\rho=-0.2, n=102, p<0.05]$. Conclusion: The study identifies that there is a very weak relationship between the influence of science and technology on the dress sense of students; however this relationship is not statistically significant.
\end{abstract}

\section{Keywords}

Polytechnic, Dress, Fashion, Sense, Science and Technology, Ghana

\footnotetext{
${ }^{*}$ Corresponding author.
}

How to cite this paper: Schall, M., \& Appiah, S. C. Y. (2016). Progressive Retrogression: Science, Technology, Dress Sense and Fashion Taste amongst Polytechnic Students in Ghana. Art and Design Review, 4, 21-29. 


\section{Background}

The quest to cover the nakedness of mankind plays a critical role in defining the original purpose and intent of dress. (Roach-Higgins \& Eicher, 1992: p. 1) have defined dress as "an assemblage of modifications of the body and/or supplements to the body". Thus dress is not only about the clothing for covering but consist of all adornments. Theoretically, researchers on dress and fashion have often isolated dress as the stimulus variable. Out of such orientation emerges inquiry into areas such as dress effects on impression formation and social perception (Lennon \& Davis, 1989) and dress effect on human behaviors (Johnson et al., 2008; Johnson \& Lenon, 2014; Johnson et al., 2014).

In attempts to understand the drivers of dress and account for the provocativeness among those who wear them, several theories have been used. Some researchers have used attribution theories (McLeod, 2010) to comprehend in their research on dress. In such studies as suggested by McLeod, see-through, short item dresses provocative appearance, skimpy dressed laced with heavy makeup (body modification) have been employed in attributing responsibility to women for their sexual assaults and experiences of sexual harassment. Meanings are thus made to persons who wear particular dress.

The symbolic interactionism perspective has been used as the framework by some researchers to examine the meanings offered to people who dress in particular way or wear particular dresses (Blumer, 1969; Mead, 1934; Stone, 1962). Fundamentally, symbolic interactionism addresses sets of questions such as "What common set of symbols and understandings has emerged to give meaning to people’s interactions?” (Patton, 2002: p. 112; Blumer, 1969). Its application to dress and looks emphasize how ones behavior relative to another person is influenced by another person's dress (Kaiser, 1997) and the meaning given to that dress (Johnson et al., 2014).

It is not uncommon to find students on various campuses of higher institutions dressed in a manner that influence people to marvel as to whether the students are in a learning environment or a represent a commune of harlots (Katlin 2009; Arzuah, 2011). It sometimes become disturbing to see students especially females with halter-tops and bare midriff, thigh underwear peeking above ultra-low-cut jeans and transparent dresses. These dress codes according to John Amaralcited by Azuah (2011); Gbadegbe \& Mawuli (2013) are "now getting out of control".

Notwithstanding, there are considerable number of students in many tertiary institutions whose dress sense or fashion taste seems to be socially acceptable. Katlin (2009) study of the Arab women has shown that it was highly accredited among the Arab women that dressing and appearance is a more critical issue for females compared to males; thus, women must have more credibility, acceptance from people and legitimacy in their dressing (Fayokun et al., 2009; Fayokun, Adedeji ,\& Oyebadi, 2009).

Dressing is essential components of human life. Since human beings are not animals, they will undoubtedly need a dress to cloth themselves. The kind of dress made by individuals is influence by many essential elements ranging from cultural, social and economic conditions (Powell \& Gilbert 2009). A person's identity is very much Identical with or his or her dress (Twigg et al., 2009). Historically, dressing or fashion style of people was very well-mannered but as history unfolds and science and technology began to take the world's centre stage, the manner of dressing has sharply changed from decency to a dress-sense of nudity. According to Toye (2003) provocative, improperdress is morally unacceptable. Lynn (2004) emphasizes that the unswerving trend or shift in emphasis notable among female students in tertiary institutions in the early to mid-20 ${ }^{\text {th }}$ century is based on the misconception that exposed skin reveals a woman's figure and creates new definition for female exquisiteness.

Young (2005) in her book Young “Throwing Like a Girl,” asserts that fashion "constructs habits of the feminine body comportment in the male-dominated society’ and that women can only attain subjectivity by adopting a position of the male subject who takes pleasure in seeing women the objectified. It is this position of women looking fashionable that sometimes is stretched beyond the acceptable. Whiles body modifications practiced by men are geared towards developing muscularity (Cafri et al. 2005a, b) paying much attention to building the upper body areas of chest and biceps (Thompson \& Cafri 2007), girls look for self-expression.

\section{The Influence of Science and Technology on Dressing Code or Fashion Taste}

The emergence of science and technology has affected various aspects of human life. Undeniably, science and technology has influence fashion which Judy is defines it as all sorts of clothing items, textiles fabrics and their study. The selection of a particular dressing code and its body adornment over another is partly influenced by technology (Edem, 2009). It is thus, not common to see students dress in their traditional and cultural apparel. 
Their dress codes have changed from the traditional fashion to the European fashion due to the influence of modernization which is brought about through science and technology. Edem (2009) attributes the modern dress as very universal amongst the youths.

Through science and technology, students could match the color combination of their dressings or choose a particular dressing sense or fashion taste based on the prevailing weather conditions. Indecent dressing mostly fueled by technology sometimes through media had made some students to dress in a manner by showing off parts of their bodies and even under wears particularly those of the ladies that need to be covered (Egwim, 2010). In the opinion of Terry (2013), any attempt to blame only women for their "provocative" dress is only a reinforcement of "stereotypical ideas of a patriarchal culture that blames" women for everything when males are the ultimate consumers of the dress women wear.

The introduction of science and technology through education by the westerners has brought variations in clothing and made clothes available to the larger community, from childhood to adulthood, with different styles and designs existing today for people and students. Interestingly, while some students copy blindly from these scientific and technological influenced-dress codes; others learn correctly on how to dress from these same technological ideas (Nenad, 2013). It has been acknowledge among some researchers that standards of attractiveness are being altered by the western world through the agency of science and technology. What constitute attractiveness is constantly being debated with stereotypical orientation where thin appearance becomes representational for women and mesomorphic but muscular appearance becomes suited for men (Karazia et al., 2013). Continued exposure to varying, contemporary social and cultural norms for appearance (through ideated images in the media) is shaping both men and women satisfaction with dress and body appearance (Blond 2008; Grabe et al., 2008) though this is more characteristic of women than for men (Buote et al., 2011). Among students, the exposure permeates every facet of schooling and academic life

It is ascertained that, more students spend unnecessary time on the media (brought about through science and technology) sometimes watching how their celebrities dress. This is often facilitated through videos, satellites and other media agents (Omede, 2011). Their dress sense is thus; influenced by their celebrities (Nenad, 2013), resulting in some cases of abuses and rapes. Terry (2013) is however of the view dress cover has little relationship with being raped or abused. It was established using a 2008 report from the Egyptian Center for Women's Rights, $83 \%$ of Egyptian women had had sexual harassment or assault at least once of which around $70 \%$ of them wore veils of some kind, particularly head scarves. Fashion style or the dress sense of students in tertiary institutions particularly polytechnics and the universities has some relationship with science and technology.

The influences are more indirectly related mostly through the mass media such as the internet, Televisions, Magazines amongst others and could either be positive or negative or both. When viewed from the objectification theory perspective, the media focus on bodies and body parts. The response of women to this theory is when some women may view their bodies from a third-person perspective and hands their bodies as objects to be looked at and assessed with the viewer's not considering the bodies as that of accomplishments (Harrison \& Fredrickson 2003).

Despite the several continuing debate among scholars, the relationship between science and technology influence and fashion taste is inconsistent. The direction and magnitude of the influence of science and technology on dress sense has not been explored in clear terms in Ghana and even across research domains. This study aims at examining the relationship between science and technology influence and students fashion taste.

\section{Methods}

\subsection{Study Setting and Research Design}

The Kumasi Polytechnic is one of the Ten Polytechnics in Ghana. It is situated in Asem within the Subin Sub Metro Council of the Ashanti region of Ghana. The polytechnic runs Tertiary programmes like Marketing, Building Technology, whiles Pre-Higher National Diploma programmes and professional professionals are additionally run. The research approach was quantitative. The study employed a descriptive cross sectional design. The study was conducted among students of the Kumasi Polytechnic main campus. The Multi-stage cluster sampling technique was adopted. The two stage approach stratified the students into four strata made up of departments: Marketing, Building Technology, Pre HND and Creative Art. After the stratification, 110 students were randomly selected for the study. The sampling of the students was done in proportion to the number in each stratum: Marketing (30) Building Technology (30), Pre HND (30) and Creative Art (20). After checking 
for consistency in the entries, eight of the responses were deleted and the sample size was 102 representing 92.7\% response rate.

\subsection{Measures}

The dependent variable for the study was "dress sense and fashion taste" while the independent variable in the study was "influence of science and technology". The dependent variable were measured by asking question "how do you evaluate the present dress sense of students with responses good bad worse". The students understanding of dress sense, students' opinion on the negative effect of science and technology on dress sense, and better dress sense than before were elicited. Questions asked included but not limited to "What is the effect of dress science and technology on dress sense with responses such as leading to loss of culture, causing harm to students, improving student dress. Thus both the dependent and independent variables were measured at nominal levels. The instrument reliability was examined after the researcher pre-tested the questionnaire on 10 students who were part-time students. The sample of 10 for the pretest is consistent with Baker (1994) who argue the acceptability of between $10 \%-20 \%$ of the sample size being appropriate for pilot testing instruments validity. Moreover the reliability test showed a Cronbach alpha of 0.73 which was found to be above the recommended 0.70 (Bagozzi \& Yi, 2012).

\subsection{Operational Definitions}

Science and Technology: This applies to all modern tools and techniques, styles that are applied in making dresses.

Dress sense: Dress sense suggest the positive or negative evaluation for dress, the qualitative assessment of its appropriateness, the sense of feeling, taste, liking, appreciation and preference for a particular dress.

Western culture: This relates to all aspect of fashion and dressing and costume that have their origins traceable to Europe and America and are commonly identified with how pop stars, celebrities and icons dress.

\subsection{Statistical Analysis}

The study results were analyzed descriptively and presented in tables and graphs as well as inferential analysis. The Pearson product-moment correlation coefficient was used in determining the relationship between the dependent and independent variables. Bi-variate analysis was done by employing the Chi-square test of significance to test the significant relationship between the variables $[p \leq 0.005]$.

\section{Results}

\subsection{Bio-Data of Respondents}

The researchers cleaned the data and excluded inconsistent responses, Thus out of the expected total of 120, the questionnaire returned was 110 . The responses rate was $91.6 \%$. However, there were 102 correct responses which have been analyzed descriptively and presented in Tables. The results of the study are presented in Tables and figures.

\subsection{Shared Views on the Current Effect of Science and Technology on Dress Sense on Students}

Student appreciation of current effect of science and technology on dress sense is fundamental to understanding how they dress now and hope to dress in the future as well as the costume they put on. A total of 82 (80.3\%) out of the 102 participants expressed their view on this variable. Table 1 shows (53.7\%) of the respondents have the view that science and technology influences better dress sense of students presently. Additionally, $46.3 \%$ hold different opinion contrary to the views of the majority. Students in the minority believe that science and technology has nothing to do with how better students dress or otherwise presently. Many female students (75.7\%) expressed their opinion on the effect of science and technology on dress sense than males (24.4\%) students. The findings show that majority $80 \%$ (16/20) of males and a minority 35.5\% (22/62) female respondents disagreed to science and technology having any negative influence on dress sense with only $20 \%(4 / 20)$ proportion of males and $64.5 \%$ (40/62) of females agreed by affirming that science and technology has facilitated better dress sense 
of students than before. Gender of the students was found not to have any statistically significant association with the opinion shared on science and technology making dress sense of Ghanaian students better in the future $\left(x^{2}=0.21, p \leq 0.05\right)$.

\subsection{The Near-Future Effect of Science and Technology on Dress Sense of Students}

The study explored the gendered perspectives on the future effect that advancements in science and technology will have on dress sense. The respondents offered their views on what will happen to dress sense of students in the few years coming as advancements continue in the field of science and technology. This has been cross tabulated and presented in Table 2.

Table 1 indicates the opinions of respondents both males and females on the future impact of science and technology on dress sense of students. The results were varied in respect of the impact that strides in science and technology will make on dress sense of students. Among the possible outcomes that advancements in science and technology will result are, loss of culture, cause harm or will rather making dress sense better in the future. The results indicate that (47.1\%) of the respondents on a single factor response hold the view that science and technology will make dress sense better in the future. According to $32.4 \%$ of the students, science and technology will rather cause harm while $20.5 \%$ share the opinion that there will be loss of culture as a result of science and technology influence in the future. Thus cumulatively those who consider the potential of science and technology in influencing dress sense by causing a loss of culture and harming harm to society account for 54 (53.0\%) of the student population studied. In respect of the gendered dimension, the variations in the opinion of male and female was very pronounce on science and technology causing loss of culture than causing harm and bettering dress sense of students. The Spearman rho correlation coefficient is -0.2 showing a negative weak correlation between gender and the near future effect of technology on dress sense.

\subsection{The Influence of Western Culture on the Beauty Concepts of Students}

Western culture has permeated into the culture of the Ghanaian people. Western culture has influenced the beauty concept of Ghanaian youth but its nature and direction of influences is crucial to the survival of the Ghanaian cherished beauty concepts and dress sense.

The results of the study (Table 3) show that 84.3\% (86/102) of the students held the view that western culture,

Table 1. Students view on the current effect of Science and Technology on making dress sense better.

\begin{tabular}{cccc}
\hline \multirow{2}{*}{ Sex } & \multicolumn{3}{c}{ Science and Technology makes dress sense better now } \\
\cline { 2 - 4 } & Agree & Disagree & Total \\
\hline Male & $4(20 \%)$ & $16(19.5 \%)$ & $20(24.3 \%)$ \\
Female & $40(48.7 \%)$ & $22(26.8 \%)$ & $62(75.7)$ \\
Total & $44(53.7 \%)$ & $38(46.3 \%)$ & $82(100 \%)$ \\
\hline
\end{tabular}

$\mathrm{X}^{2}=0.21$.

Table 2. Gender and the near-future effect of Science and Technology on dress sense.

\begin{tabular}{|c|c|c|c|c|}
\hline Sex & Loss Culture & Cause harm & Be made better & Total \\
\hline Male & $6(5.8 \%)$ & 15 (14.8\%) & $19(18.7 \%)$ & $40(39.3 \%)$ \\
\hline Female & 15 (71.4\%) & 18 (17.6\%) & 29 (28.4\%) & $62(60.7 \%)$ \\
\hline Total & $21(20.5 \%)$ & 33 (32.4\%) & 48 (47.1\%) & $102(100)$ \\
\hline
\end{tabular}

$\rho=-0.212, n=102, p<0.05$.

Table 3. Gender and the effect of Western culture on the beauty concepts of students.

\begin{tabular}{cccc}
\hline & Negative Effect of Western culture on beauty concept of students & \\
\hline Gender of Youth & Yes & No & Total \\
\hline Male & $35(34.3 \%)$ & $5(4.9 \%)$ & $40(39.3 \%)$ \\
Female & $51(50.0 \%)$ & $11(10.7 \%)$ & $62(60.7 \%)$ \\
Total & $86(84.3 \%)$ & $16(15.6 \%)$ & $102(100 \%)$ \\
\hline
\end{tabular}


depicted in the form of pop culture and celebrity dress has influenced the beauty concept of students negatively. Only $15.7 \%$ judged that science and technology has no influence on the beauty concepts of students. The results suggest that while $87.5 \%$ (35/40) of male student admit that science and technology presently affects the beauty concepts and dress sense of students negatively, a relatively smaller percentage (82.3\%) of female student share the same opinion with their male counterpart. The Chi square test of association suggest that there is no statistically significant association between the gender of the students and their opinion on whether western culture has any negative influence the beauty concepts of Ghanaian students in terms of dressing $\left(x^{2}=0.505, p \leq 0.05\right)$.

\subsection{Science and Technology and Changes in Body Covering Types}

Several factors account for the variations in body covering. Key among such drivers is science and technology. The result on whether youth were in the known of established/traditional system of body covering prior to the present day influence of science and technology has been explored and presented Figure 1.

Majority $91 \%$ of polytechnic students studied agreed that, there was an established system of body of covering among the youth during the early traditional days. The minority representing 9 percent said there was no established system of covering among the youth during the early traditional days. This implies that students were in the position to know the changes that have taken place on dress sense over the period.

Knowledge on the changes in indigenous and contemporary clothing and dressing among polytechnic students were explored. The results presented in Figure 2 shows respondents' agreement to whether or not there have

\section{Established system of body covering among the youth during the early traditional days}

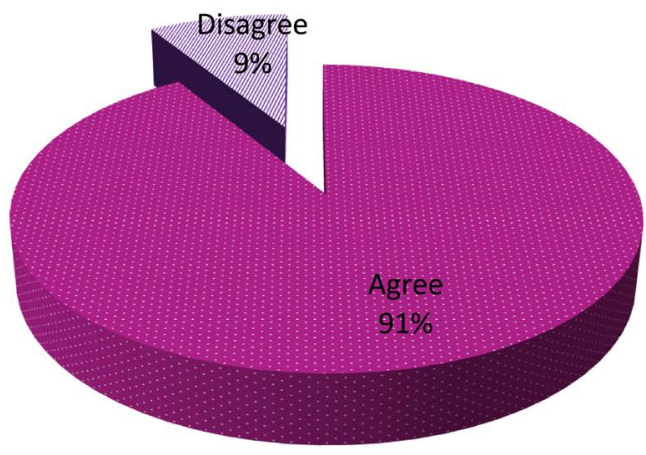

Figure 1. Established system of body covering among the youth during the early traditional days.

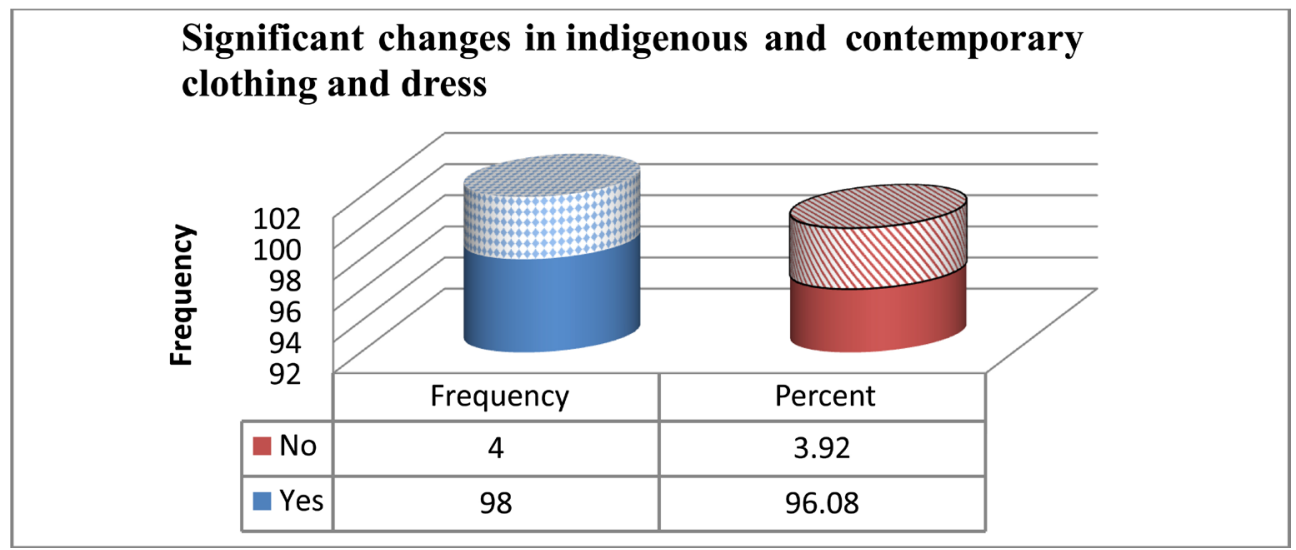

Figure 2. Significant changes in indigenous contemporary clothing and dress. 
been significant changes in indigenous and contemporary clothing and dress over the last decade. The responses from the field exposed that, 4 representing 3.92 percent out of the 102 students disagreed with this assertion. The majority made up of 98 respondents representing a percentage of 96.08 agreed with the assertion and attributed this to influence of science and technology.

\section{Discussion}

The aim of this study was to explore the effect that the progression in science and technology is having on dress sense and the beauty concepts of Ghanaian polytechnic students. Adopting the descriptive cross sectional and two stage sampling technique, we found that there was no statistically significant differences in the outcomes of the effect of science and technology on the beauty concepts and dress sense on the basis of gender. The findings of this study provide evidence that fails to fully support the position that the sex of students influences their shared opinions about the negative effects of science and technology on dress sense and beauty concept. Though Fayokun et al. (2009) and Katlin (2009) have opine that women evaluation of dress sense and beauty concept is more pronounced than men, in this study, women who endorsed science and technology negative influence on dress sense are in small proportion compared to males (82.3\% vs. $87.5 \%)$ despite the fact that there was no statistically significant difference between males and female on their opinion on the effect of science and technology on dress sense.

The magnitude of the influence of gender on student shared views and opinions on how western culture will influence the beauty concept of students in the near future is only $4 \%$ (coefficient of determination, $r^{2}$ ). Thus, in the opinion of the students, science and technology in the near future will account only $4 \%$ variability in the dress sense of students. They do not see science and technology influencing the dress sense of students much. Our finding does not find support convincingly for Egwim (2010) whose study finding suggested that science and technology fuels the negative dress sense (beauty concept) of students and will continue to do same. The difference between our finding and that of previous study was study, in our preset study we isolated western culture as a single variable distinct from science and technology. Most studies do not place a distinction when examining drivers of dress sense and mix western culture and science and technological advancement as a single factor.

The effect of science and technology on dress sense of students in the near future has an inverse magnitude of impact though insignificant. Again, in this study, the idea that science and technology will have impact on loss of culture of students in the future as expressed by some respondents supports Edem (2009) findings in his study. However, the results of this study indicates that the view expressed by Edem is not strongly upheld by the polytechnic students since only $20.6 \%$ of the respondents hold similar idea as established in this study. Many however attest to the findings made by Nenad (2013) that science and technology has opened wide varieties of dress combinations to students; thus, presenting an opportunity for making the dress sense of students to be made better in the coming years than now (Blond 2008; Grabe et al., 2008). According to majority of the respondents, the dress sense will even be made better than now with the influence of science and technology.

There are also considerable numbers of respondents (32.4\%) whose opinions contradict with Nenad findings but goes in line with Egwin study that science and technology has led to modernization which is causing harm on dress sense. This is because; students especially the females dress indecently exposing their bodies which need to be well covered similar idea as The responses of almost a third of the respondents support Egwin (2010) finding that science and technology will cause more harm than before in the coming years ahead.

Thus, it cannot fully be ascertained that science and technology will lead to loss of culture, cause harm or will better students' dress sense in the future as endorsed in the study conducted by Edem (2009, 2010), Jevtic (2013) and Nenad (2013) accordingly. Thus, in this study, there is uncertainty as to whether science and technology will have influence on loss of culture, cause harm or would rather lead to a better dress sense. This is attributable to the varying taste and preference and the different levels of exposure students are opened to as well as the differing socialization orientations and dress sense perspectives shared by students. The pace of the scientific and technological onslaught on Ghanaian dress and fashion industry will give direction to the effect it will have on student dress sense and beauty concepts.

Moreover, the idea that science and technology would continuously have negative effects on beauty contest, body decoration and dress sense in the future as expressed by majority of respondents supports Edem (2010) finding that as a result of foreign influence, cultural dimensions of students reflected in the way they use to dress has been replaced by European style of dressing. Participants consider this adds more beauty to their natural 
make-up. As a result, students dress mode especially the females contradict with the dress mode culturally accepted in the country.

Despite more than half (53.7\%) holding the strong judgment that science and technology has influenced dress sense in a better way; the extant body of literature provides divergent views on how science and technology influences dress sense whether in a better manner or otherwise. Among researchers, there is a continuing contrasting findings without clear direction of the influence of science and technology on dress sense and fashion taste among students. Nenad (2013) is ambivalent and points out that the influence of science and technology on dress sense could be good or bad. According to his study, some students respond positively to science and technology by choosing the right outfit that is socially accepted in the community. Notwithstanding; others react negatively by putting an apparel which disposes their bodies which ought to be covered (Toye, 2003; Lynn, 2004). Similar views are shared in this study.

This shows inconclusiveness as to whether science and technology influence has helped better students' apparel or dress sense or not and whether it has such a potential to effect that change or make it worse in the future. It all sums up to a value judgment of the student in considering a dress product of science and technology and how the student adorns with it as a beauty or homeliness. Notwithstanding the views expressed by majority of the respondents, the Spearman correlation coefficient (or $\rho$ ) indicated a weak negative relationship $(\mathrm{r}=-0.2, n=$ $102, p<0.05$ ) between science and technology and better dress sense in the future.

This goes hand in hand with Nenad (2013) study; hence, one cannot confidently ascertain that science and technology will influence dress sense in a better direction. This is because the pendulum of opinions assembled in this study swings to and fro from better dress sense in some cases to negative dress sense in other cases. One could also match this finding with Powell \& Gilbert (2009) opinion that other factors apart from science and technology such as economic, cultural and social conditions also influence dress sense of students.

Another interesting finding from the study indicates that due to science and technology, majority of students dress in a manner that accords with the prevailing conditions under which they find themselves. This implies that students will prefer a particular dress code for funeral, another for naming ceremonies and other occasions and a different sense of dress for school and its related activities or any other social gatherings. Thus, one could accept that there is no universal monolithic attire that can be imposed on every occasion attended by majority of the students. This matches hand in hand with Egwin (2010) study that students choose color combinations depending on prevailing conditions existing at a particular place and time.

\section{Limitation of Study}

This study is possibly limited by a social desirability response bias resulting from the tendency of students to provide socially acceptable answers. This was dealt with adequately to guarantee a reliable data by the researchers structuring the questionnaire to identify responses which were inconsistent. Additionally, filter questions included in the questionnaire aided in identifying socially desirable response.

\section{Implications of the Study}

The findings from this study have significant implications for education on proper dress sense in order to reduce the growing indecency among tertiary students. The growing decline in modesty and the increasing spread of negative fashion orientation brought by western influence and pop culture as well as science and technology underscores the need for a proper dress orientation from the home and the other agents of socialization. This is aimed at limiting the spread of nudity and impropriety in dressing. This study is of great importance for, personality definition, cultural identity, national representation as it has a significant impact on family, nation building and has consequences for redefining the social fiber and morality grade of the country. Future research is recommended to be made with a large sample on the determinants of dress among tertiary students.

\section{Competing Interests}

The authors declare no competing interests.

\section{Funding}

This study did not receive funding from any agency. The authors funded the study themselves. 


\section{References}

Azuah, S. (2011). Factors Influencing Takoradi Polytechnic Students' Choice of Clothing. Unpublished Thesis, Takoradi Polythecnic, Takoradi.

Bagozzi, P. R., \& Yi, Y. (2012). Specification, Evaluation, and Interpretation of Structural Equation Models. Academy of Marketing Science, 40, 8-34. http://dx.doi.org/10.1007/s11747-011-0278-x

Baker, T. L. (1994). Doing Social Research ( $2^{\text {nd }}$ ed.). New York: McGraw-Hill Inc.

Blumer, H. (1969). Symbolic Interactionism: Perspective and Method. Englewood Cliffs, NJ: Prentice-Hall, Inc.

Buote, V., Wilson, A., Strahan, E., Gazzola, S., \& Papps, F. (2011). Setting the Bar: Divergent Sociocultural Norms for Women's and Men's Ideal Appearance in Real-World Contexts. Body Image, 8, 322-334. http://dx.doi.org/10.1016/j.bodyim.2011.06.002

Edem, B. D. (2009). Clothing and Fashion in Ghanaian Culture: A Case Study among the Akans. An Unpublished Dissertation, Kumasi: School of Graduate Studies, Kwame Nkrumah University of Science and Technology.

Egwim, C. (2010). Indecent Dressing among Youths. http://www.es/networld.com/webpages/features

Fayokun, K. O., Adedeji, S. O., \& Oyebade, S. A. (2009). Moral Crisis in Higher Institutions and the Dress Code Phenomenon. Online Submission, 6, 58-66.

Gbadegbe, R. S., \& Mawuli, Q. (2013). The Impact of Indecent Dressing on the Academic Performance of Students in Tertiary Institutions, a Case Study of Ho Polytechnic in Ghana. Journal of Education and Practice, 4.

Grabe, S., Ward, L. M., \& Hyde, J. S. (2008). The Role of the Media in Body Image Concerns among Women: A Meta-Analysis of Experimental and Correlational Studies. Psychological Bulletin, 134, 460-476. http://dx.doi.org/10.1037/0033-2909.134.3.460

Jevtic, N. (2013). Influence of Media on Teenagers. http://www.studymode.com/essays/Influence-Of-Media-On-Teenagers-1724487.html

Johnson, K. K. P., \& Lennon, S. J. (2014). The Social Psychology of Dress. In J. B. Eicher (Ed.), Encyclopedia of World Dress and Fashion (Online). New York: Berg.

Johnson, K., Lennon, S. J., \& Rudd, N. (2014). Dress, Body and Self: Research in the Social Psychology of Dress. Fashion and Textiles, 1. http://dx.doi.org/10.1186/s40691-014-0020-7

Kaiser, S. B. (1997). The Social Psychology of Clothing: Symbolic Appearances in Context. New York, NY: Fairchild.

Karazia, B., van Dulmen, M., Wong, K., \& Crowther, J. (2013). Thinking Meta-Theoretically about the Role of Internalization in the Development of Body Dissatisfaction and Body Change Behaviors. Body Image, 10, 433-441. http://dx.doi.org/10.1016/j.bodyim.2013.06.005

Lennon, S. J., \& Davis, L. L. (1989). Clothing and Human Behavior from a Social Cognitive Framework Part I: Theoretical Perspectives. Clothing and Textiles Research Journal, 7, 41-48. http://dx.doi.org/10.1177/0887302X8900700406

Lynn, H. G. (2004). Fashioning Modernity; Changing Meanings of Clothing in Colonial Korea. Journal of International and Area Studies, 11, 75-93.

McLeod, S. A. (2010). Attribution Theory. http://www.simplypsychology.org/attribution-theory.html

Mead, G. H. (1934). Mind, Self and Society. Chicago, IL: University of Chicago Press.

Omede, J. (2011). Indecent Dressing on Campuses of Higher Institutions of Learning in Nigeria: Implications for Counseling. Journal of Emerging Trends in Educational Research and Policy Studies (JETERAPS), 2, 228-233.

Patton, M. Q. (2002). Qualitative Research and Evaluation Methods (3rd ed., pp. 66-272). Thousand Oaks, CA: Sage.

Powell, J. L., \& Gilbert, T. (2009). Aging Identity a Dialogue with Postmodernism. Hauppauge, NY: Nova Science Publishers.

Roach-Higgins, M. E., \& Eicher, J. B. (1992). Dress and Identity. Clothing and Textiles Research Journal, 10, 1-8. http://dx.doi.org/10.1177/0887302X9201000401

Stone, G. P. (1962). Appearance and the Self. In A. M. Rose (Ed.), Human Behavior and Social Processes: An Interactionist Approach (pp. 86-118). New York: Houghton Mifflin.

Twigg, J., Powell, J. L., \& Gilbert, T. (2009). Aging Identity a Dialogue with Postmodernism. Hauppauge, NY: Nova Science Publishers.

Young, I. M. (2005) On Female Body Experience: “Throwing Like a Girl” and Other Essays. New York: Oxford University Press. http://dx.doi.org/10.1093/0195161920.001.0001 